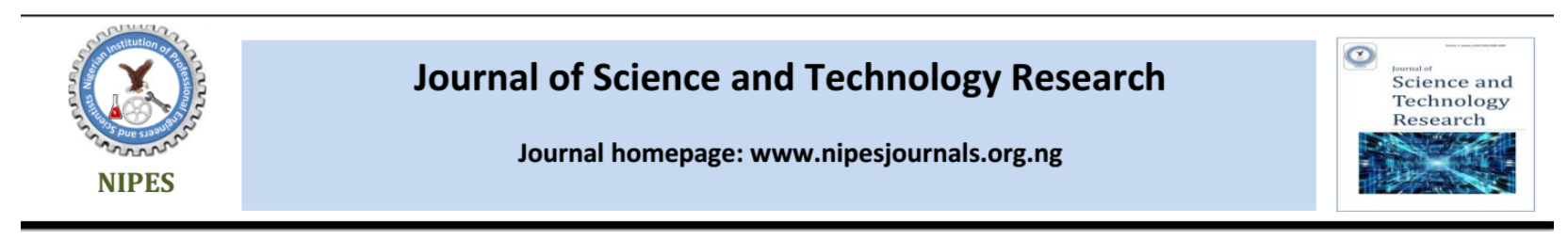

\title{
Kinetics of the Extraction of Oleoresin from Ginger: Influence of Particle Size and Extraction Time Effects
}

\author{
A.O. Ameh ${ }^{a}$, M.S. Olakunle ${ }^{a}$, H.U. Shehu ${ }^{b}$ and T. Oyegoke ${ }^{a, c, *}$ \\ ${ }^{a}$ Chemical Engineering Department, Ahmadu Bello University Zaria, Nigeria. \\ ${ }^{\mathrm{b}}$ Chemical Engineering Technology Department, Kaduna Polytechnic, Kaduna, Nigeria \\ 'Laboratoire de Chimie, ENS, l’Universite de Lyon, Lyon 69007, Lyon, France. \\ Corresponding Email: *ToyeseOyegoke@gmail.com
}

\section{Article Info}

Keywords:

Evaluation, Extraction, Ginger, Modeling, Oleoresin and

Curve-fitting

Received 25 March 2020

Revised 03 April 2020

Accepted 02 May 2020

Available online 01 June 2020

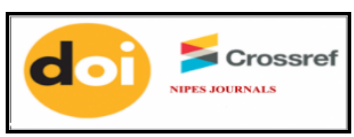

https://doi.org/10.37933/nipes/2.2.2020.14

https://nipesjournals.org.ng ISSN-2682-5821/@ 2020 NIPES Pub. All rights reserved.

\begin{abstract}
The effects of particle sizes and extraction time on the solvent extraction of oleoresin were studied to obtain data for process control and optimization. Extraction was carried out using ethanol as a solvent and at a constant temperature of $40^{\circ} \mathrm{C}$. Ginger particle sizes considered were 1200, 850, 600, 425 and 250 microns at extraction times of 10, 20, 30, 40, 50, 60 and 70 minutes. Experimental data generated were fitted to an empirical model to determine the kinetic parameters. It was found that, for each particle size, the yield of oleoresin increased with increasing extraction time up to an optimum time after which the yield remained constant. Also, the optimum extraction was found to have increased with decreasing particle size. Furthermore, the maximum oleoresin yield was found to be dependent on particle size, viz-a-viz, smaller particle sizes favored greater yield. These results were reflected in the constants of the Patricelli equation ( $K$ and $\tau$ ). Fitting the experimental data to the empirical model indicated a good fit as represented by the $R 2$ values. The ginger extract was characterized using FTIR.
\end{abstract}

\section{Introduction}

Zingiber officinale Roscoe, commonly known as ginger, is a member of the Zingiberaceae family. Ginger is an underground rhizome of the ginger plant with a firm, striated texture. Most Zingiberaceae family spices are fibrous-rooted, a perennial herb that is widely cultivated in some tropical regions such as India, China, Nigeria, Australia and Jamaica [1]. Ginger species possess aromatic properties and have commercial importance. There are two valuable extracts of ginger, essential oil which varies between $0.8-4.2 \%$ and oleoresin in the range of about $7 \%$ depending on its origin, habitat and agronomic treatment of culture [2]. The pungent taste of ginger is due to nonvolatile phenylpropanoid derived compounds, particularly gingerols and shogaols. Ginger contains a variety of vitamins and minerals.

Oleoresins are the pure concentrated extract form of a spice or herb. This spice derivative has the same character and property of the spice it is obtained from. Oleoresin compounds, such as 6gingerol and its derivatives obtained from the root of ginger possess high antioxidant activity [3]. The antioxidants are micronutrients that have gained interest in recent years due to their ability to neutralize the actions of free radicals [4]. They reproduce the character of the respective organic spice and organic spice oil fully. It contains the volatile as well as non-volatile constituents of spices. 
Oleoresins can replace whole/ground spices without impairing any flavor and aroma characteristic. The solvents used for extraction are non-aqueous and maybe polar (alcohols) or nonpolar (hydrocarbons, carbon dioxide). Oleoresins are like perfumery concretes, obtained especially from flowers, and to perfumery resinoids, which are prepared also from animal secretions.

Some researchers such as Yang et al. [5] and Zhiyi et al. [6] have confirmed the historical practical use of essential oils; the 'fragrant pharmacy' contains compounds with an extremely broad range of biochemical effects.

One important method of essential oil extraction from plants is the steam distillation; it preserves the original qualities of the plant. Akhihiero et al. [7] report that smaller particle sizes of the plant raw material yield more essential oil than larger sizes. However, the amount of oil release depends on its volatility and distillation time in the absence of airtight collection system. For very volatile essential oils, the amount of oil that could be released is a function of the distillation time [7]. Conversely, essential oils that could be obtained in the steam distillation method, oleoresins abound in heavier, less volatile and lipophilic compounds, such as resins, waxes, fats and fatty oils. Gummooleoresins (oleo-gum resins, gum resins) occur mostly as crude balsams and contain also watersoluble gums. Most oleoresins are used as flavors in food and beverages, and medicine and perfumes industries. The increased prominence of oleoresins over natural spices is due to the advantages that oleoresins have over the spices themselves. These advantages include increased economic gain, more uniform flavor and concentration, and lack of microbial contamination [8].

The solvent extraction is a widely employed technique designed to separate soluble polyphenols from plant tissue using a solvent. Commonly used solvents for extraction of oleoresin from plant tissue are water, ethanol, methanol, and acetone among others [9]. Other novel extraction methods like microwave-assisted extraction (MAE), supercritical fluid extraction and pressurized solvent extraction have drawn significant research attention in the last decade [10]. Research has shown that there is a scientific curiosity and certain popularity concerning screening essential oils and extracts from plants to detect natural compound's characteristics and antioxidant activity as well as antimicrobial activity, used medicinally all over the world [11].

Although many studies have been carried out on the determination of the active compounds of ginger and the development and implementation of the different operating conditions for ginger oleoresin recovery, little attention seems to have been given to the optimization of the various extraction variables (e.g. the appropriate solvent, operating temperature, contact time, and quantity of sample among others). Evidence of the systematic study for the optimization of the method is also limited. However, Mukherjee et al. [12] approached to optimize the process conditions, in his study, three influential process parameters namely ethanol $\left(\mathrm{C}_{2} \mathrm{H}_{5} \mathrm{OH}\right)$ proportion $(\%)$, temperature $\left({ }^{\circ} \mathrm{C}\right)$ and extraction time (min) were taken into consideration.

Kanadea and Bhatkhandeb [13] also reported the efficacy of the solvent extraction method for obtaining ginger oil, while Ok and Jeong [14] reported on optimum conditions for obtaining 6Shogaol-rich extract from ginger. Further research is needed to study the influence of parameters such as solvent type and proportion, extraction temperature and contact time to get the optimum condition for the extraction of oleoresin from ginger with high yield of oleoresin and high antioxidant properties.

This gives the motivation for the present study; to focus on ginger which is abundant in Nigeria and considering its benefits to the pharmaceutical and food industry. Hence, this research aims to determine the effect of particle size and extraction time on the extraction of oleoresin from ginger 
rhizome; and to model the extraction process using the principles of curve fitting method using the MATLAB algorithm.

\section{Methodology}

\subsection{Model Formulation}

The ginger rhizomes used for the extraction of oleoresin were sourced from Jaba Local Government Area, in the southern part of Kaduna State, North-Central region of Nigeria.

\subsection{Preliminary Analysis}

Three preliminary analysis carried out includes identification of the ginger rhizomes species, its proximate analysis and Fourier Transform Infrared (FTIR) analysis which are present in details as follows:

\section{a. Identification of Ginger rhizome Specie}

The ginger rhizome samples were taken to the Biological Science Department of Ahmadu Bello University Zaria for identification where the ginger rhizomes were identified as zingiber officinale (V/N: 2261).

\section{b. Proximate Analysis of Ginger rhizome}

Proximate analysis was carried out to determine the composition of the ginger rhizomes at the Department of Agronomy, Ahmadu Bello University, Zaria. Other materials used such as distilled water, ethanol, and ethyl acetate were sourced from the Department of Chemical Engineering, Ahmadu Bello University, Zaria.

\section{c. Fourier Transform Infrared of Ginger rhizome}

The extracted oleoresin was then characterized using FTIR (ABB3000) at the Center for Mineral Research and Development, Kaduna Polytechnic, Kaduna, Nigeria. From which, the Fourier transform infrared (FTIR) was used to identify the characteristic functional groups in the extract. A small quantity $(5 \mathrm{mg})$ of the extract was dispersed in dry potassium bromide $(\mathrm{KBr})$. The mixture was thoroughly mixed and pressed at a pressure of 6 bars within 2 min to form a $\mathrm{KBr}$ thin disc. Then the disc was placed in a sample cup of a diffuse reflectance accessory. The sample was scanned from $4000-400 \mathrm{~cm}^{-1}$.

\subsection{Production of Oleoresin}

This section covers the procedure of extraction of oleoresin from ginger, and it is as follows:

\section{a. Ginger pre-treatment}

The ginger rhizomes were washed thoroughly with tap water to remove sand and dirt. The light outer skin was scraped off using a knife and later cut into tiny pieces. All samples so prepared were then dried in an air-circulating oven at a temperature of $40^{\circ} \mathrm{C}$ in a laboratory and ground manually into power using a grinder, followed by screening using a set of sieves into various particle size 
ranges $1200,850,600,425$ and 250 microns. The ground screened samples were stored in an airtight polythene bag as stock samples in a cool dry place until required for extraction.

\section{b. Oleoresin extraction}

The dry ginger powder was put directly into the solvent (ethanol) and heated under reflux inside a round bottom flask with a water bath, to ensure temperature control and uniform heating $\left(40^{\circ} \mathrm{C}\right)$. The hot water bath sat on a combined hot plate and stirrer. Both the water bath and solvent mixture were mixed throughout the extraction. The round bottom flask had three ports. The water-cooled condenser was connected directly to the round bottom flask using one of the ports. The other ports were used to insert/remove a stir bar or a thermometer for checking the temperature. Since the condenser was not closed at the top, the system was at atmospheric pressure. Operating at a low pressure reduced the risk of breaking glassware or other accidents.

Five different particle size ranges of $1200,850,600,425$ and 250 microns of the powdered ginger samples were used to study the effect of particle size at a constant temperature of $40^{\circ} \mathrm{C}$, solid-liquid ratio of $10 \mathrm{~g} / 100 \mathrm{ml}$, and varying extraction time between 10 and 70 minutes. Ethanol was used as the solvent at different times using the same extraction conditions. After each run, the solvent was separated from the oleoresin by distillation to obtained solvent-free oleoresin.

\subsection{Kinetic Studies}

The mass transfer of oleoresin during solvent extraction can be described by a first-order model [18]. The kinetic equation is:

$$
\tau \frac{d Y}{d t}=K-Y
$$

Where, $\mathrm{Y}=$ amount $(\mathrm{g})$ of oleoresin extracted per $100 \mathrm{~g}$ dry ginger (initially at time, $\mathrm{t}=0, \mathrm{Y}=0$ ) , $\mathrm{K}=$ the maximum amount (in $\mathrm{g}$ ) of oleoresin which can be extracted in the process per $100 \mathrm{~g}$ dry ginger, $\mathrm{t}=$ the extraction time $(\mathrm{min}), \tau=$ the time constant for the process $(\mathrm{min})$.

This model was a lumped form of Fick's Law of Diffusion [15]. Solving the differential equation gave:

$$
Y(t)=K\left[1-e^{\frac{-t}{\tau}}\right]
$$

The maximum yield $(\mathrm{K})$ and time constant, $\tau$ (i.e. the time when the maximum oleoresin yield became constant) depends on the solvent used and the ratio $(\mathrm{R}, \mathrm{ml}$ of solvent used per $\mathrm{g}$ dry ginger used). This equation matches Patricelli et al. [16]'s model without a washing stage.

\subsection{Process Model Development, Validity and Significances}

An algorithm was developed with the use of MATLAB program for the fitting of the experimental data collected into the theoretical models stated above in Equation 2. In which, the resulting model (obtained from the fitting of the data into the theoretical model) accuracy assessed via the use of statistical analysis, where the validity and accuracy of the model developed were ascertain via the use of R-squared and Adjusted R-squared criteria. This was done for different sets of experimental data collected for the different particles' sizes. The algorithm used for the curve fitting, model 
development and model validation were presented in the appendix. The algorithm was run on a machine with configuration: hp pavilion 15, intel process, core i3, 8 GB RAM and 1 TB hard disk.

\section{Results and Discussion}

\subsection{Proximate analysis of the ginger rhizome}

The proximate analysis of the ginger rhizome is as shown in Table 1. The proximate composition of the ginger rhizome compares favorably with those in literature, only with slight variations. These variations could be attributed to the season, climate, storage condition and species of the ginger. The dry ginger rhizome (Table 1) showed a moisture content of $6.41 \%$ which was found to be lower compared to what was obtained by El-Ghorab et al. [17] as $10.0 \pm 0.007 \%$, but similar to $6.37 \pm$ $0.0 \%$ that was obtained by Otunola et al. [18]. The major component of the dry ginger sample was its crude carbohydrate content with a high total carbohydrate value of $59.76 \%$ and crude fiber content of $9.74 \%$. Protein content is important from the nutritional point of view.

Table 1: Proximate Analysis of Dry Ginger Rhizome

\begin{tabular}{cc}
\hline Nutrients & Composition (\%) \pm 2 st. deviation (SD) \\
\hline Moisture content & 6.41 \\
Crude Carbohydrate & 59.76 \\
Dietary fiber & 9.74 \\
Crude Protein & 9.82 \\
Crude Fat & 8.81 \\
Ash & 5.46 \\
\hline
\end{tabular}

Moreover, the protein content of the dried ginger sample was 9.82\%. The works of Mbaeyi-Nwaoha et al. [19] and Otunola et al. [18] showed a slightly lower protein content compared to this value (9.42\% and $8.58 \%$ respectively), while that of Latona et al. [20] showed higher value $(34.13 \%)$. It should be noted that the low moisture content of the ginger samples significantly raised the values of other constituents. The crude fat content of the dry ginger sample was $8.81 \%$, whereas the ash content is $5.46 \%$, which is comparable to values obtained in literature, where the total ash content of dry ginger was reported to be $6.1 \%$ [17].

\subsection{FTIR Analysis}

The results of the FTIR analysis of the extracted oleoresin are presented in Figure 1 which displaced several peaks. In which the identified peak indications were presented in Table 3 where all the functional groups that they depicted were summarized.

Table 3. Functional compounds of fresh elephant ginger rhizome analyzed by using FTIR

\begin{tabular}{llll}
\hline No & Wavelength $(\mathbf{c m})$ & \multicolumn{1}{c}{ Vibration type } & \multicolumn{1}{c}{ Functional compound } \\
\hline 1 & 625 & O-H bond & Phenol \\
2 & 1034 & C-OH stretch & Alcohol primer $\left(-\mathrm{CH}_{2} \mathrm{OH}\right)$ \\
3 & 1080 & C-O-C stretch alkyl-aryl ether & Ether (R-O-R) \\
4 & 1137 & C-O-C stretch dialkyl ether & Ether (R-O-R) \\
5 & 1265 & C-O-C strech venyl ether & Ether (R-O-R) \\
6 & 1373 & CH3 bond sym & Alkena, methyl $-\mathrm{CH}_{3}-$ \\
7 & 1450 & Ring aromatic strech $(4 \mathrm{p})$ & $\mathrm{C}=\mathrm{C}$ aromatic \\
8 & 1512 & Ring aromatic strech $(4 \mathrm{p})$ & $\mathrm{C}=\mathrm{C}$ aromatic \\
11 & 2854 & OH stretch; H-bonded & Carboxylic acid $(\mathrm{RCOOH})$ \\
12 & 2924 & OH stretch; H-bonded & Carboxylic acid $(\mathrm{RCOOH})$ \\
13 & 3418 & OH strech; H-bonded & OH \\
\hline
\end{tabular}




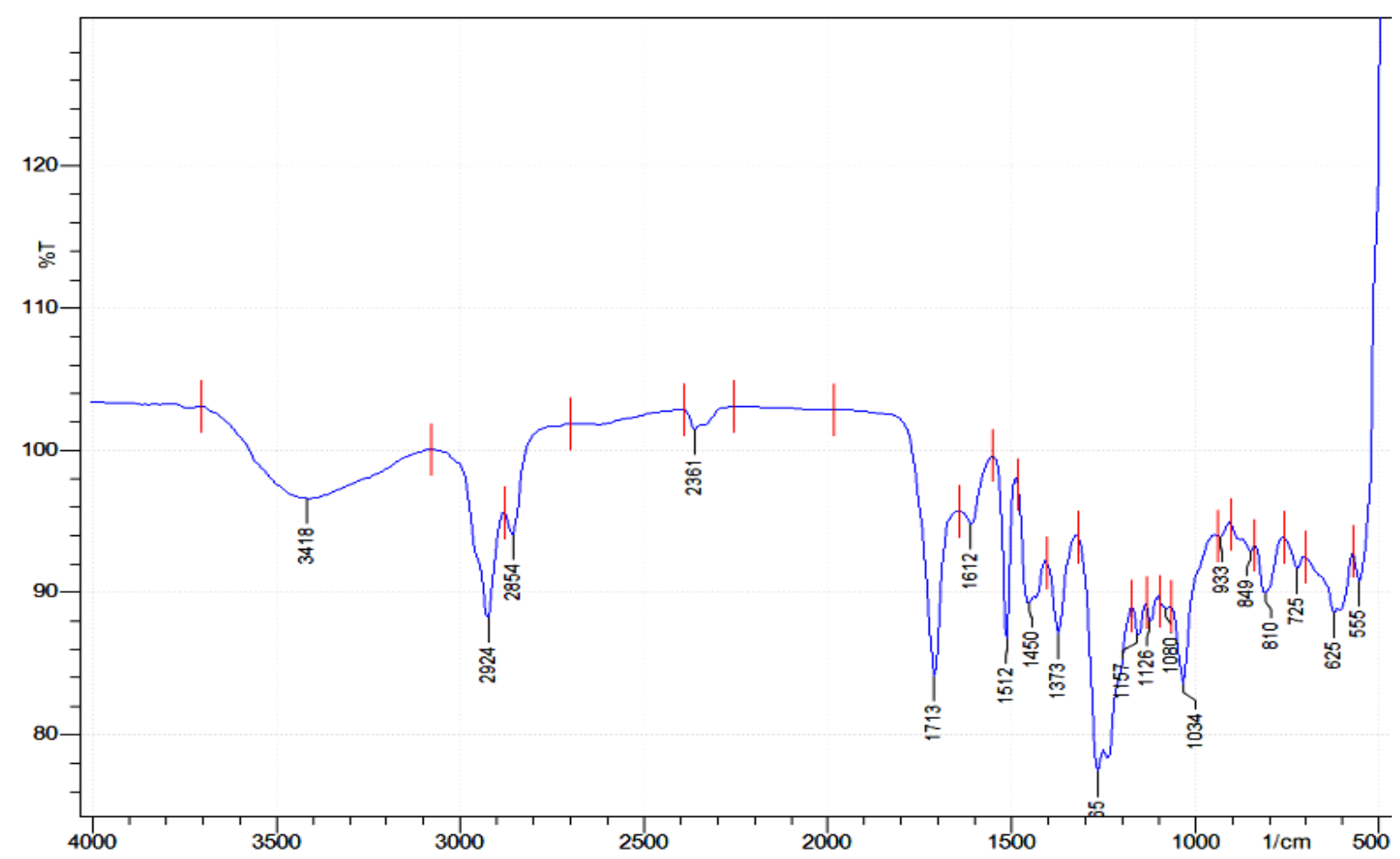

Figure 1: FTIR Spectra for oleoresin.

The results indicated the presence of several functional groups such as phenolic, ether, aromatic, carboxylic acid, and alcohols which were found to be similar to the kind of observation made in the report of Purnomo et al. [21] and Jayanudin and Rochmadi [22] on FTIR analysis of their ginger extracts.

The wideband observed in Figure 1 at $3418 \mathrm{~cm}^{-1}$ corresponds to the $\mathrm{OH}$ stretching vibration of primary alcohol. The band observed at $2924 \mathrm{~cm}^{-1}$ corresponds to $\mathrm{O}-\mathrm{H}$ stretch in $\mathrm{H}$-bonded in carboxylic acid $(\mathrm{RCOOH})$. Likewise, the band observed at $1080 \mathrm{~cm}^{-1}$ corresponds to $\mathrm{C}-\mathrm{O}-\mathrm{C}$ stretching vibrations of $1^{\mathrm{o}}$ alcohol (alcohol primer $-\mathrm{CH}_{2} \mathrm{OH}$ ). All the bands agree with literature peak values reported by Purnomo et al [21], Jayanudin and Rochmadi [22].

\subsection{Effects of Extraction Time and Particle Size on Oleoresin Extraction from Ginger}

The effect of particle size (Y) and extraction time (x) were evaluated with the aid of the statistical plot represented in Figure 1 which shows the relationship between various variables. The resulting solution or outcome of the algorithm is shown in Figure 1.

For all particle sizes considered (ranging from 250 to 1200 microns) as shown in Figure 2, it was observed that as the extraction time increases, their yield increases respectively. Although, it was also confirmed that as the particle size reduces from 1200 to 250 microns, their extraction rate rises significantly which is evident in a graphical form in Figure 2. This could be attributed to the large surface area possessed by the smaller particle-sized oleoresins. It was confirmed that the yield of 5.7, 6.2, 7.9, 8.3 and 9.5 units was obtained for $1200,850,600,425$ and 250 microns respectively after 10 minutes of extraction which confirms that there is a high yield at a lower particle size of 250 microns. 


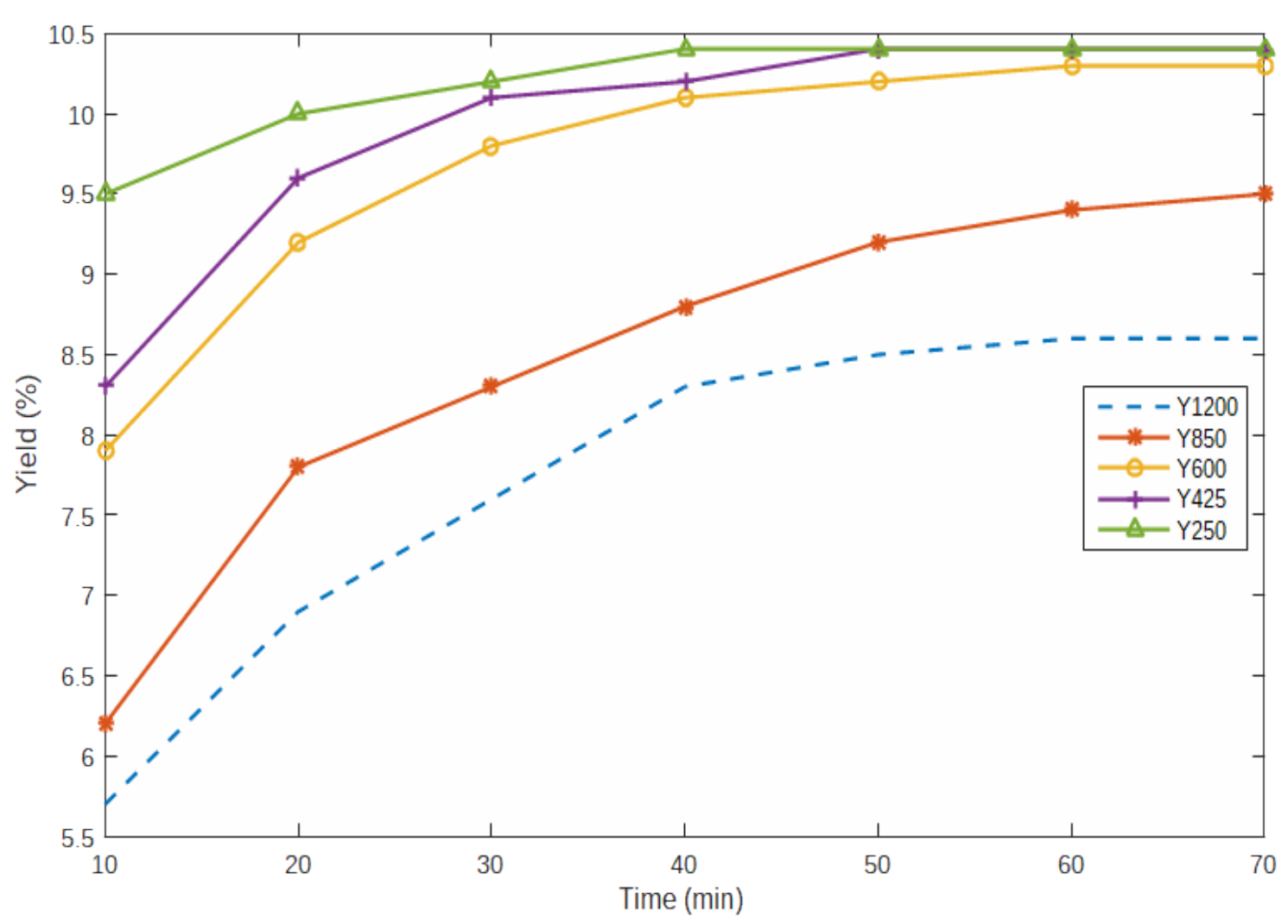

Figure 2: Effect of different particle size range with time on the yield in oleoresin extraction

Moreover, the extraction curves in Figure 2 indicated the exponential growth of extraction rate for all the examined particle ranges (ranging from 250 to 1200 microns) which agreed with the literature $[12,16]$.

\subsection{Results of Model Development and Analysis}

The results of the coefficients of the model developed, R-squared value and Adjusted R-squared value from the model validation analysis carried-out in MATLAB are presented in Table 2. From the results, it was deduced that the $\mathrm{K}$ (the maximum amount (in gram) of oleoresin which can be extracted in the process per $100 \mathrm{~g}$ dry ginger) decreased (from 10.32 to 8.457) as the particle size of the ginger increased (from 250 to $1200 \mu \mathrm{m}$ ) which agrees with curve presented on Figure 2 (showing the effect of particle size on yield with the different trend lines presented). It was found that 250 microns resulted in the highest maximum extractable oleoresin from $100 \mathrm{~g}$ of dry ginger as $10.32 \mathrm{~g}$ while 1200 micron recorded the least as $8.457 \mathrm{~g}$ oleoresin per $100 \mathrm{~g}$ of dry ginger.

Furthermore, it was deduced from Table 2 that an increase in the particle size of the ginger will always increase in the time constant $(\tau)$. This implies that as the particle size rises in order of 250 , $425,600,850$ to 1200 microns, their time constant $(\tau)$ values increased from 4.032, 6.315, 7.030, 9.851 , to 10.22 minutes respectively. It also be said the increase in the particle size of the ginger is contributing to reducing the rate of extraction due to the increased time constant observed (which has an indirect relation with the rate of extraction as presented in Equation 1). 
It may be deduced from Table 2 that increasing the particle size of the ginger had increased in the time constant $(\tau)$. That is, as the particle size rises from $250,425,600,850$ to 1200 microns, their time constant values increased from 4.032, 6.315, 7.030, 9.851, to 10.22 minutes respectively.

Table 2: Models developed and its validity

\begin{tabular}{|c|c|c|}
\hline $\begin{array}{l}\text { Size } \\
\text { (micron) }\end{array}$ & Model developed & Statistical Analysis \\
\hline 1200 & $\begin{array}{l}\text { Y1200(x)= K*[1-exp }(-(\mathrm{x} / \mathrm{T}))] \\
\text { Coefficients (with } 95 \% \text { confidence bounds): } \\
\mathrm{K}=8.457 \\
\mathrm{~T}=10.22\end{array}$ & $\begin{array}{c}\text { sse: } 0.5378 \\
\text { rsquare: } 0.9259 \\
\text { dfe: } 5 \\
\text { adjrsquare: } 0.9111 \\
\text { rmse: } 0.3280\end{array}$ \\
\hline 850 & $\begin{array}{l}\mathrm{Y} 850(\mathrm{x})=\mathrm{K} *[1-\exp (-(\mathrm{x} / \mathrm{T}))] \\
\text { Coefficients (with } 95 \% \text { confidence bounds): } \\
\mathrm{K}=9.192 \\
\mathrm{~T}=9.851\end{array}$ & $\begin{array}{l}\text { sse: } 0.5665 \\
\text { rsquare: } 0.9309 \\
\text { dfe: } 5 \\
\text { adjrsquare: } 0.9171 \\
\text { rmse: } 0.3366\end{array}$ \\
\hline 600 & $\begin{array}{l}\text { Y600(x)= K*[1-exp }(-(\mathrm{x} / \mathrm{T}))] \\
\text { Coefficients (with } 95 \% \text { confidence bounds): } \\
\mathrm{K}=10.14 \\
\mathrm{~T}=\quad 7.03\end{array}$ & $\begin{array}{l}\text { sse: } 0.2606 \\
\text { rsquare: } 0.9437 \\
\text { dfe: } 5 \\
\text { adjrsquare: } 0.9324 \\
\text { rmse: } 0.2283\end{array}$ \\
\hline 425 & $\begin{array}{l}\mathrm{Y} 425(\mathrm{x})=\mathrm{K}^{*}[1-\exp (-(\mathrm{x} / \mathrm{T}))] \\
\text { Coefficients (with } 95 \% \text { confidence bounds): } \\
\mathrm{K}=10.29 \\
\mathrm{~T}=\quad 6.315\end{array}$ & $\begin{array}{l}\text { sse: } 0.1334 \\
\text { rsquare: } 0.9622 \\
\text { dfe: } 5 \\
\text { adjrsquare: } 0.9546 \\
\text { rmse: } 0.1633\end{array}$ \\
\hline 250 & $\begin{array}{l}\mathrm{Y} 250(\mathrm{x})=\mathrm{K} *[1-\exp (-(\mathrm{x} / \mathrm{T}))] \\
\text { Coefficients (with } 95 \% \text { confidence bounds): } \\
\mathrm{K}=10.32 \\
\mathrm{~T}=4.032\end{array}$ & $\begin{array}{l}\text { sse: } 0.1019 \\
\text { rsquare: } 0.8519 \\
\text { dfe: } 5 \\
\text { adjrsquare: } 0.8223 \\
\text { rmse: } 0.1428\end{array}$ \\
\hline
\end{tabular}

Moreover, Table 2 shows that the extraction yield model for 1200, 850, 600, 425 and 250 microns show R-squared values of 92.6, 93.1, 94.4, 96.2 and 85.2\% while the adjusted R-squared values were $91.1,91.7,93.2,95.5$ and $82.23 \%$ respectively.

Based on the results collected for both R-squared and adjusted R-squared values in Table 2, it can be said that model for the extraction of oleoresin from 425 microns ginger will give the best prediction and its output will be reliable due to its high R-squared and adjust R-squared value recorded as 96.2 and $95.5 \%$ respectively. Although, other models for 1200, 850 and 600 microns will also give good predictions, but it cannot be compared to that of 425 microns.

\section{Conclusion}

This paper showed that for each particle size, yield of oleoresin increases with increasing extraction time up to an optimum time after which the yield remained constant. Also, the optimum extraction was found to increase with decreasing particle size: thus, the Patricelli parameter (i.e. time constant), $(\tau)$ and the maximum amount of oleoresin which can be extracted $(\mathrm{K})$ was found to be a particle size-dependent parameter. This study identified that smaller particle sizes will highly favor greater yield. The kinetics of the extraction was found to have shown a good fit for the Patricelli equation. 
A.O. Ameh et al. / NIPES Journal of Science and Technology Research 2(2) 2020 pp. 142-151

\title{
Nomenclature
}

\author{
$\mathrm{t} \quad$ Extraction time (min), (which is equal to $\mathrm{x}$ ) \\ Y \\ rsquare $\quad$ R-square value from statistical analysis \\ rmse $\quad$ Root-mean-square value obtained from the statistical analysis
}

$\mathrm{K} \quad$ The maximum amount (in $\mathrm{g}$ ) of oleoresin which can be extracted in the process per $100 \mathrm{~g}$ dry ginger,

adjrsquare $\quad$ Adjusted R-square value from statistical analysis

dfe $\quad$ Degree of freedom of model

Greek letters

$\tau \quad$ Time constant for the process (min) (i.e. the time when the maximum oleoresin yield became constant)

\section{References}

[1] Bartley J.P., Jacobs A.L. 2000. Effects of drying on flavor compounds in Australian- grown ginger (Zingiber officinale). J. Sci. Food Agric. 80, pp. 209-215.

[2] Azian N.M., Sazalina M. S., and Rizan H. M. R. 2001. Essential Oil and Active Ingredients Extraction from Ginger Plants. Annual Progress Report Centre of Lipids Engineering \& Applied Research, Kuala Lumpur, Malaysia.

[3] Stoilova, I., Krastanov, A., Stoyanova, A., Denev, P. and Gargova, S., 2007. Antioxidant activity of a ginger extract (Zingiber officinale). Food Chemistry, 102(3), pp.764-770.

[4] Cardenas E, Packer L. 1996. Handbook of Antioxidants. Plenum, New York. pp. 127-131.

[5] Yang, Y. Gharaibeh, A. Hawthorne, S. B. and Miller, D. J. 1995. "Combined Temperature \& Modifier Effects on Supercritical CO2 Extraction Efficiencies of Polycyclic Aromatic Hydrocarbons from Environmental Samples", Analytical Chemistry, 67(3):641-646.

[6] Zhiyi, L. Xuewu, L. Shuhua, C. Xiaodong, Z. Yuanjing, X. Yong, W. and Feng, X. 2006 “An Experimental and Simulating Study of Supercritical CO2 Extraction for Pepper Oil”, Chemical Engineering and Processing, 45: 264-267.

[7] Akhihiero E.T., Ayodele B.V. and Akpojotor G.E. 2013. Effect of particle size and temperature variation on the yield of essential oil from lemongrass using steam distillation. African Journal of Physics 6, pp. 105-112.

[8] Burdock, G.A., 2016. Fenaroli's handbook of flavor ingredients. CRC press.

[9] Jakopič, J., Veberič, R., Štampar, F. 2009. Extraction of phenolic compounds from green walnut fruits in different solvents. Acta Agriculturae Slovenica, 93 (1):11 - 15.

[10] Mandal V, Mohan Y, Hemalatha S. 2007. Microwave-Assisted Extraction - An Innovative and Promising Extraction Tool for Medicinal Plant Research, Pharmacognosy Reviews, 1(1):7 - 18

[11] Hasan H.A., Rasheed R AM, Abd Razik B.M, Rasool Hassan B.A. 2012. Chemical Composition and Antimicrobial Activity of the Crude Extracts Isolated from Zingiber Officinale by Different Solvents. Pharmaceut Anal Acta 3: 184.

[12] Mukherjee S., Mandal N., Dey A., and Mondal B. 2014. An approach towards optimization of the extraction of polyphenolic antioxidants from ginger (Zingiber officinale), J Food Sci Technol.; 51(11): 3301-3308.

[13] Kanadea R. and Bhatkhandeb D. S. 2016. Extraction of ginger oil using different methods and effects of solvents, time, temperature to maximize yield, International Journal of Advances in Science Engineering and Technology, 4(3): $241-244$.

[14] Ok S. and Jeong W. 2012. Optimization of Extraction Conditions for the 6-Shogaol-rich Extract from Ginger (Zingiber officinale Roscoe), Prev Nutr Food Sci., 17: 166-171.

[15] Halim R., Danquah M.K., and Webley P.A. 2012. "Extraction of Oil from Microalgae for Biodiesel Production: A Review." Biotechnology Advances" 30: 709-732. 
A.O. Ameh et al. / NIPES Journal of Science and Technology Research 2(2) 2020 pp. 142-151

[16] Patricelli A., Assogna A., Casalaina A., Emmi E., Sodini G. 1979. "Fattori che influenzano l'estrazoine dei lipidi da semi decorticate di girasole", La Rivista Italiana Delle Sostanze Grasse, 56, 136-142.

[17] El-Ghorab, A.H., Nauman, M., Anjum, F.M., Hussain, S. and Nadeem, M. 2010. A Comparative Study on Chemical Composition and Antioxidant Activity of Ginger (Zingiber officinale) and Cumin (Cuminum cyminum). J. Agric. Food Chem., 58, 8231-8237 8231, DOI:10.1021/jf101202x

[18] Otunola, G.A., Oloyede, O.B., Oladiji, A.T. and Afolayan, A.J. 2010. Comparative analysis of the chemical composition of three spices - Allium sativum L., Zingiber officinale Rosc. And Capsicum frutescens L. commonly consumed in Nigeria. African Journal of Biotechnology, 9(41), pp.6927-6931. DOI: 10.5897/AJB10.183.

[19] Mbaeyi-Nwaoha, I.E., Okafor, G.I. and Apochi, O.V. 2013. Production of oleoresin from ginger (Zingiber officinale) peels and evaluation of its antimicrobial and antioxidative properties, African Journal of Microbiology Research, 7(42), pp. 4981-4989, DOI: 10.5897/AJMR2013.6125

[20] Latona, D.F., Oyeleke, G.O. and Olayiwola, O.A. 2012. Chemical Analysis of Ginger Root. IOSR Journal of Applied Chemistry, 1(1), pp.47-49.

[21] Purnomo, H., Jaya, F. and Widjanarko, S. B. 2010. The effects of type and time of thermal processing on ginger (Zingiber officinale Roscoe) rhizome antioxidant compounds and its quality, International Food Research Journal, 17: 335-347.

[22] Jayanudin J. and Rochmadi R. 2017. Encapsulation of red ginger oleoresin (ZINGIBER OFFICINALE VAR RUBRUM) with chitosan as wall material. International Journal of Pharmacy and Pharmaceutical Sciences, 9(8): 29 - 34.

\section{Appendix}

The algorithm employed is presented below:

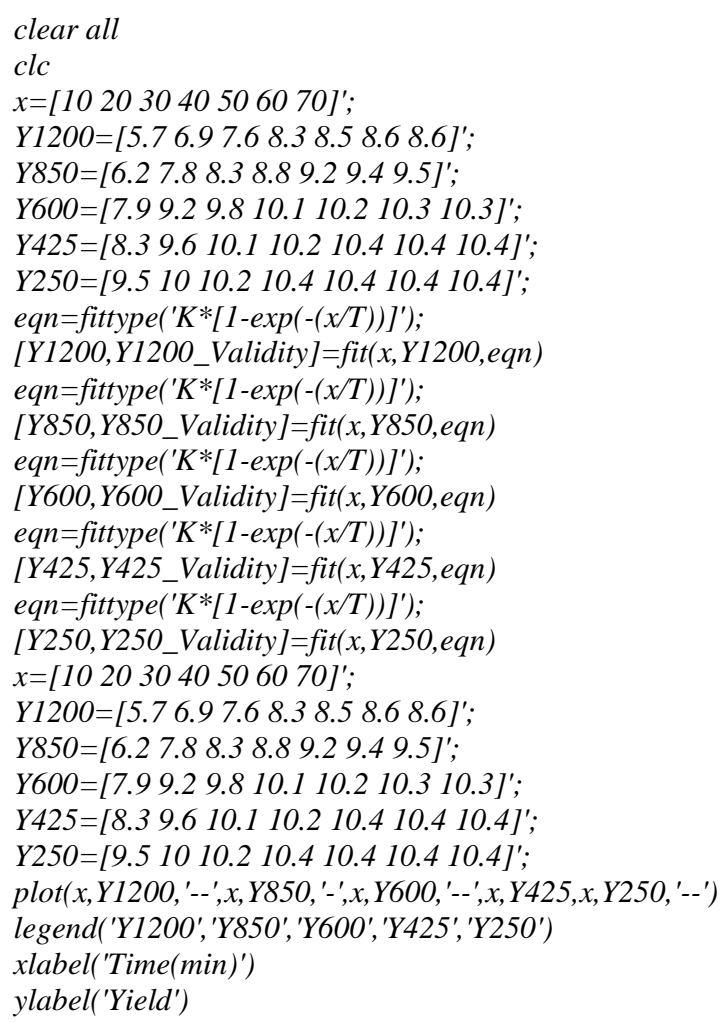

